International Journal of Child, Youth and Family Studies (2012) 4: 376-395

PARENTAL MONITORING AND RISKY BEHAVIOR IN BAHAMIAN YOUTH

\author{
Giavana Jones, Xinguang Chen, Bonita Stanton, Veronica Dinaj-Koci, \\ Lynette Deveaux, Sonja Lunn, Nanika Brathwaite, M. Perry Gomez
}

\begin{abstract}
Adolescent involvement in risk behaviors is a concern that crosses geographical and cultural boundaries. Research has identified a number of factors that influence child behavior outcomes. This study explored the role of perceived neighborhood problems, parent-child relationships, and parental monitoring, as they relate to engagement in risk behaviors among a sample of 497 Bahamian early adolescents. Contrary to the hypothesized direction, results of the latent growth model showed an increase in perceived parental monitoring over the four-year period. Consistent with our hypotheses, adolescents who reported greater monitoring reported less involvement in sexual activity, less involvement in physical fights, and less alcohol consumption. Positive interactions between parent and child also significantly predicted the initial status and rate of change of parental monitoring.
\end{abstract}

Keywords: adolescent risk behavior, parental monitoring, Caribbean

Acknowledgements: We thank the National Institute of Mental Health (NIMH) for support for this research (R01 MH069229). We are also grateful to the Ministry of Education and the students who participated in the study. Finally, we would like to thank Dr. Dennis Jackson, University of Windsor, for his assistance in the early development of the paper.

Correspondence concerning this paper should be addressed to Dr. Bonita Stanton, M.D., Department of Pediatrics, Pediatric Prevention Research Center, Wayne State University School of Medicine, 3901 Beaubien Boulevard, Detroit, Michigan, U.S.A. Email: BStanton@dmc.org 
International Journal of Child, Youth and Family Studies (2012) 4: 376-395

Giavana Jones is a doctoral candidate in the Department of Psychology, University of Windsor, 401 Sunset Avenue, Windsor, Ontario, Canada, N9B 3P4. E-mail: jones123@uwindsor.ca

Xinguang (Jim) Chen, M.D., Ph.D. is a methodologist and Professor within the Pediatric Prevention Center, Wayne State University School of Medicine, 3901 Beaubien Boulevard, Detroit, Michigan, U.S.A. E-mail: jimchen@med.wayne.edu.

Bonita Stanton, M.D. is a pediatrician and Vice Dean for Research, Wayne State University School of Medicine, 3901 Beaubien Boulevard, Detroit, Michigan, U.S.A. E-mail: BStanton@med.wayne.edu.

Veronica Dinaj-Koci is a doctoral student in the Department of Psychology at Wayne State University, 3901 Beaubien Boulevard, Detroit, Michigan, U.S.A. E-mail: ar0687@wayne.edu.

Lynette Deveaux is local coordinator for the Focus on Youth program Bahamas at the Ministry of Health, Royal Victoria Gardens, East Hill Street, Nassau, Bahamas. E-mail:

lc.deveaux@hotmail.com.

Sonja Lunn is the assistant coordinator for the Focus on Youth program Bahamas at the Ministry of Health, Royal Victoria Gardens, East Hill Street, Nassau, Bahamas. E-mail: slunn@coralwave.com.

Nanika Brathwaite is a statistician with the Ministry of Health, Royal Victoria Gardens, East Hill Street, Nassau, Bahamas. E-mail: nanikab@hotmail.com.

M. Perry Gomez, M.D. is Director of the Bahamas National HIV/AIDS Programme, Princess Margaret Hospital, Ministry of Health, Bahamas. E-mail: docgomez47@gmail.com. 
Adolescent involvement in problem behaviors occurs across the globe. Historically, adolescence has been characterized as an intensely emotional period during which youth struggle with defining their identity as they move from childhood to adulthood (Erickson, 1968). It is a time of exploration and pushing boundaries. Some risk behaviors that are found in adolescents include alcohol and drug use and abuse, fighting, gang involvement, and early involvement in sexual behavior (Carroll et al., 2006; Tapert, Aarons, Sedlar, \& Brown, 2001). Such behaviors are considered "risky" or problematic because of the ramifications to the individual, their immediate family, and/or the wider community. These behaviors place youth at risk for threats to their well-being including alcohol and drug dependency or addiction, legal problems, health problems, teenage parenthood, or premature death. Once initiated, some of these problems persist through adulthood (Brook et al., 2004; Karp, O’Louglin, Paradis, Hanley, \& Difranza, 2005; Park, Weaver, \& Romer, 2009; Trim, Meehan, King, \& Chassin, 2007). Additionally, because of the substantial emotional and financial investments required to address such undesirable consequences, families of the adolescents and the wider community are also greatly impacted (Greenwood, Model, Chiesa, \& Rydell, 1996; Hoffman, 2006).

Research suggests that for some youth, involvement in problem behaviors may have been present from early childhood, even as early as the preschool years (Moffitt, 1993). For others, risk-taking behaviors are only associated with adolescence, oftentimes not posing problems for these individuals as they move into adulthood (Steinberg, 1999). Regardless of the timing of onset, certain factors have been commonly associated with adolescent problem behaviors. For more than four decades, researchers have been studying these risk factors to better understand the roots of problem behaviors (Steinberg \& Morris, 2001).

While specific personality factors, including impulsivity, sensation-seeking, and temperament, have consistently been found to be associated with problem behavior in adolescence (Arnett, 1992; Lynam \& Miller, 2004; Pharo, Sim, Graham, Gross, \& Hayne, 2011; Shaw, Bell, \& Gilliom, 2000; Steinberg, 2007), human development occurs within a nested set of interconnected systems (Bronfenbrenner, 1979). That is, social and environmental influences moderate these and other individual characteristics, thus impacting child development including the propensity for risk-taking behavior. Variables such as the parent-child relationship, supervision and monitoring, parenting style, peer groups, and neighborhood conditions have all been explored as they relate to child behavioral problems (Aalsma, Liu, \& Wiehe, 2011; DeaterDeckard \& Dodge, 1997; Dodge, Pettit, \& Bates, 1994; Leventhal \& Brooks-Gunn, 2011; Loeber \& Dishion, 1983; Sameroff, Peck, \& Eccles, 2004). From an ecological perspective, adolescent behavior is best understood as a function of the systems that encompass these variables and other environmental level factors in which they are embedded including the roles of the neighborhood and community, parent-child relationships, and peers.

\section{Neighborhood Influences}

Neighborhood has a profound influence on child development (Leventhal \& BrooksGunn, 2000). Leventhal and Brooks-Gunn propose three broad and complementary categories 
International Journal of Child, Youth and Family Studies (2012) 4: 376-395

useful to our understanding of neighborhood influences: (a) norms and collective efficacy, (b) institutional resources, and (c) relationships and ties.

Norms and collective efficacy is a structural construct that assesses the role of socioeconomic status, residential stability, and the ethnic composition of neighborhoods. Institutional resources assess the presence, accessibility, and quality of various community resources including childcare availability, medical facilities, social supports, and learning opportunities. Relationships and ties address the family structure, specifically parental stability and the home environment. Impaired outcomes in child development have been linked to disruptions in any of these attributes of neighborhood organization (Leventhal \& Brooks-Gunn, 2000; Mrug \& Windle, 2009; Romano, Tremblay, Boulerice, \& Swisher, 2005; Sampson, 1997). For example, children raised in impoverished neighborhoods have been found to be more likely to be physically aggressive (Leventhal \& Brooks-Gunn, 2011; Romano et al., 2005) and delinquent (Chung \& Steinberg, 2006; Mrug \& Windle, 2009) and to manifest conduct problems and antisocial behavior (Edwards \& Bromfield, 2009).

\section{Parent-child Relationships}

Researchers have identified several social processes that promote healthy adolescent development, one of which is effective parenting (Malecki \& Demaray, 2006; Masten, 2001; Ryan, Miller-Loessi, \& Nieri, 2007). Effective parenting is characterized by positive and healthy parent-child relationships. Healthy parent-child relationships are marked by the parents' engagement in the child's life, the use of positive reinforcement, and open and positive communication patterns (Dishion \& McMahon, 1998). Other characteristics of a healthy parentchild relationship include trust, responsiveness, warmth, and sensitivity (Barnard, Morisset, \& Spierker, 1993). Such positive parenting practices minimize, and sometimes obliterate, the negative effect of neighborhoods on children's behavior (Emery \& Forehand, 1996; VanderbiltAdriance \& Shaw, 2008). Conversely, ineffective parenting practices are often characterized by poor parent-child interactions, insufficient monitoring, and harsh physical discipline.

Additionally, ineffective parenting is a risk factor for child and adolescent problem behaviors (Patterson, Debaryshe, \& Ramsey, 1989; Romano et al., 2005). Specifically, for example, poor parent-child relationships have been associated with delinquency in childhood and adolescence (Frick, Christian, \& Wootton, 1999; Keijsers, Loeber, Branje, \& Meeus, 2011).

\section{Parental Monitoring}

Parental monitoring refers to the parents' awareness of and ability to track their child's whereabouts and activities (Dishion \& McMahon, 1998). It is a function of the parent-child relationship (Dishion \& McMahon, 1998), in that healthy parent-child relationships foster open communication, which in turn has been shown to be associated with increased parental monitoring, particularly as it relates to the child's willingness to check in with the parents (Kerns, Aspelmeier, Gentzler, \& Grabill, 2001; Stattin \& Kerr, 2000). Parental monitoring is associated with positive outcomes in childhood (Leventhal \& Brooks-Gunn, 2000). Specifically, it is positively associated with adolescent school performance and inversely associated with adolescent involvement in deviant behaviors (Dishion, Capaldi, Spracklen, \& Li, 1995). Parental monitoring has been linked with decreased involvement in and delayed introduction to various 
International Journal of Child, Youth and Family Studies (2012) 4: 376-395

negative behaviors in adolescence, including substance use and abuse (Chilcoat \& Anthony, 1996; Li, Stanton, \& Feigelman, 2000; Richards, Miller, O’Donnell, Wasserman, \& Colder, 2004; Stattin \& Kerr, 2000), delinquency (Griffin, Botwin, Scheier, Diaz, \& Miller, 2000; Richards et al., 2004; Smetana, Crean, \& Daddis, 2002), and sexual experiences (Huebner \& Howell, 2003; Li et al., 2000; Meschke \& Silbereisen, 1997; Wight, Williamson, \& Henderson, 2006).

Parental monitoring becomes even more salient in families who live in neighborhoods with diminished resources and/or increased rates of crime and violence (Beyers, Bates, Pettit, \& Dodge, 2003; Byrnes, Miller, Chen, \& Grube, 2011; Jarrett, 1999). Jarrett (1999) suggests that parents need to be more aware of their child's whereabouts to decrease the likelihood that their children will succumb to the risks associated with stressed neighborhoods. Thus increased parental monitoring is a means to keep children safe, particularly in communities where violence is prevalent. Research has validated this supposition, providing evidence that increased monitoring among children raised in poor neighborhood conditions results in better outcomes than their peers who are not as closely monitored (A. Baldwin, C. Baldwin, \& Cole, 1990; Chilcoat \& Anthony, 1996; Gonzales, Cauce, Friedman, \& Mason, 1996).

Whereas parental monitoring, by definition, has to do with the parents' awareness of the child's whereabouts, an important aspect of the monitoring process is also the degree of communication between parent and child (Eaton, Krueger, Johnson, McGue, \& Iacono, 2009; Stattin \& Kerr, 2000). Whether or not the child is providing information on his or her whereabouts is critical to the parental monitoring process. Although some research suggests that communication by the youth with their parents plays a large role in the monitoring process, substantial evidence underscores the importance of parental efforts in this process (Soenens, Vansteenkiste, Luyckx, \& Goossens, 2006). Regardless of the initiator of the process, parental monitoring is an important part of parenting in promoting positive outcomes and decreasing the likelihood of a child's engagement in negative behaviors.

Parental monitoring is often assessed among middle-to-late adolescents in relation to the adolescents' involvement in certain behaviors; however research also supports the importance of parental monitoring among pre-adolescents for positive adolescent behavioral outcomes (Chilcoat \& Anthony, 1996). Rates or degrees of monitoring activities are likely to change as the child moves through different developmental stages. Research to date has generally revealed a decrease in parental monitoring as children age, particularly for children in at-risk populations (Dishion, Nelson, \& Bullock, 2004; Stoolmiller, 1994). This change reflects both parent withdrawal and the natural shifts that occur in adolescent development as peers become a more powerful influence (Dishion \& McMahon, 1998).

\section{Bahamian Population}

The Bahamas is comprised of more than 20 inhabited islands and is located about 50 miles south of Florida, United States of America. Although once a colony of Britain, it is now an independent nation, with a population of about 325,000 (Department of Statistics, Bahamas, 2005). New Providence, with a land mass of 80 square miles, houses about $70 \%$ of the entire Bahamian population (Gomez et al., 2002). Similar to other densely populated cities, parts of 
International Journal of Child, Youth and Family Studies (2012) 4: 376-395

New Providence are home to high rates of poverty, violence, and disease (Department of Statistics, Bahamas, 2004).

Taking an ecological approach to understanding adolescent behavior, this study explores the role of neighborhood (resources and problems), parent-child relationships, and parental monitoring in adolescence, particularly as it relates to the engagement of young people in risky problem behaviors. The research questions guiding the analyses are:

1. Do neighborhood problems and the parent-child relationship at baseline predict the initial status and trajectory of parental monitoring over a four-year period?

2. Does the intercept and trajectory of parental monitoring predict future childhood behaviors namely fighting, alcohol usage, and early sexual involvement?

Based on the parental monitoring literature, this manuscript seeks to explore three hypotheses:

- Overall parental monitoring would decrease as the child ages.

- Higher reported parental monitoring would predict less child behavior problems.

- Stronger parent-child relationships will be associated with higher parental monitoring at baseline and over the four-year period.

\section{Method}

\section{Sample and Procedures}

Data used for these analyses are a subset of data collected as part of a randomized trial of the HIV risk prevention intervention, Focus on Youth in the Caribbean (FOYC), which was conducted in 15 elementary schools on New Providence, Bahamas. Of the total 1,340 students who were included in the study, only the students who participated in the control condition were included in this sample. The FOYC trial involved the random assignment of schools to one of three conditions: two versions of an HIV prevention intervention and an environmental promotion intervention that served as the control. At baseline the students in the sample used for the analyses in the present study were from the Grade 6 classes of five elementary schools assigned to the control condition. The final sample included 269 females and 228 males for a total sample of 497 students at baseline. The students in this sample had a mean age of 10.40 (SD $=.64)$ at baseline.

The project was approved by Institutional Review Boards at Wayne State University and also the Ministry of Health (Bahamas). Ministry of Education officials also granted permission for schools to be included in the study. All schools were invited to participate although only the first 15 to respond were used in the project. Permission and assent was required from both parents and students respectively before any information was collected. Both parents and students completed questionnaires that assessed basic demographic information; knowledge of HIV, including prevention and transmission; academic, family, and neighborhood conditions; participation in, as well as intentions and expectations for, risky and protective behaviors; parentchild relationship; and parental monitoring. 
International Journal of Child, Youth and Family Studies (2012) 4: 376-395

A paper and pencil questionnaire was the primary tool for collecting information. This was administered in a group format in classrooms at each of the schools. Questions were read out loud by the researcher. To ensure confidentiality, pre-assigned, unique ID numbers were used throughout the project for tracking, organization, and storage of the data.

\section{Measures}

The Bahamian Youth Health Risk Behavioral Inventory (BYHRBI) is a cultural adaptation of the Youth Health Risk Behavior Inventory (Stanton et al., 1995). It assesses: (a) demographic information; (b) basic knowledge of condom usage, HIV transmission, healthy sex practices; (c) behavioral history, which includes sexual history, alcohol and drug history; and (d) perceptions, intentions, and expectations regarding risk and protective behaviors (Cole et al., 2007). The subtests used for analyses were from the student questionnaire and include: neighborhood conditions, parent-child communication/relationship, parental monitoring, and three questions that target the individual student's current [or past] involvement with alcohol, fighting, and sex.

Neighborhood problems. This scale consists of nine statements to assess the frequency of violence, alcohol usage, and drug usage present in the student's environment (e.g., "How often have you seen a person who lives in your neighborhood drink alcohol?”). The students respond to the questions on a three-point Likert scale ranging from 1 (Very Often) to 3 (Never). However the values were reverse-coded, and thus, higher scores indicated more problems in the neighborhood. The internal consistency for these nine items $=.901$.

Parent-child relationships. This scale of 19 statements requests students to rate their agreement with various statements (e.g., "My parent is a good listener"; "I am very satisfied with how my parent and I talk together”) on a five-point Likert scale ranging from 1 (Yes) to 5 (No). For some questions, the values are reverse-coded to ensure that all responses were positively directed such that higher scores are indicative of a stronger relationship. The internal consistency for these 19 items $=.908$.

Parental monitoring. The eight items constituting this scale request students to rate their agreement with statements about their parents' knowledge of their whereabouts (e.g., “my parents/guardians know where I am after school”) on a five-point Likert scale ranging from 1 (Never) to 5 (Always). The internal consistency for these eight items $=.841$ at year one, .748 at year two, .899 at year three, and .769 at year four.

Child behavior problems. This is a latent (composite) variable with three indicators derived from students' responses to the following questions. Response options were either Yes or No:

- Fight: "In the last six (6) months, have you been in a physical fight, other than with your brother or sister?"

- Alcohol usage: "In the last six (6) months, have you had a drink of alcohol, beer, wine, rum, or bush rum or liquor (not including when you are taking communion)?”

- Sex: "Have you ever had sex?" 
International Journal of Child, Youth and Family Studies (2012) 4: 376-395

\section{Data Processing and Statistical Analysis}

Data were manually entered into the computer. The double entry procedure was used for quality control purposes. Missing data were imputed using the MCMC method (Schafer, 1997). Before any analyses were run, the data were checked for accuracy and then for missing values; the missing values analysis was run in PASW SPSS 18 and the data was found to be missing completely at random.

Latent Growth Modeling (LGM) is a statistical procedure that allows for the examination and prediction of both individual and group level changes over time. It is one of the Structural Equation Modeling (SEM) techniques, where two key parameters, intercept and slope, estimate the growth trajectory of an outcome measure at different time points (Preacher, Wichman, MacCallum, \& Briggs, 2008). The intercept represents the initial status of the outcome variable and is typically set at " 0 ". The slope represents the linear rate of change in the outcome variable and can be set incrementally to correspond with the time points at which the outcome variable has been measured (Preacher et al., 2008). Modeling analyses were conducted using Mplus (version 5.1), which provides estimation of the maximum likelihood (ML) function. A conditional LGM was the statistical analysis selected to examine growth in parental monitoring over four years. Two time invariant covariates (TIC) were included to help explain the between individual variance in the intercept and slope estimates.

The intercept and slope (latent constructs) were based on four indicators: parental monitoring score over a four-year period. Factor loadings on the intercept for all four indicators were set at 0 ; loadings on the slope for the first two indicators were set sequentially from $0-1$, while the final two years were not constrained and were allowed to be estimated. The time invariant covariates - neighborhood problems, and parent-child relationship - were also included in the model. Paths from both covariates were allowed to be estimated for both intercept and slope latent factors.

Two growth models were assessed: The first was used to account for fit of the basic growth model, that is without the two covariates (Figure 1), and to determine whether parental monitoring is associated with risk behavior outcomes. The second model expanded upon the first to include the two covariates (Figure 2) and to assess the relationship between parental monitoring and risky behavior after controlling for the influences of the neighborhood and the parent-child relationship.

\section{Results}

The data for the present analyses were collected over a four-year period. Data from 497 students were included in these analyses; $54.1 \%$ of these students were female. In year one, the ages of students ranged from 9 to 14 years (Grade 6) with 10-year-olds representing 61.4\% of the participants.

Of the students who reported missing a day (or more) of school at year one, $1.4 \%$ missed school due to suspension, and 3.9\% reported playing "hooky". However, in year four (Grade 9 for most students), $16.3 \%$ of the students who missed a day (or more) reported suspension as the 
International Journal of Child, Youth and Family Studies (2012) 4: 376-395

reason and another 3.4\% reported playing "hooky". In year one, 36\% of the participants reported being in a fight as compared to the $26.4 \%$ of the students in year four. As it relates to alcohol consumption, $23.5 \%$ and $27.1 \%$ reported drinking alcohol in year one and year four respectively. Finally, in year one $3.6 \%$ of the students reported having sex; this number increased to $17.2 \%$ by year four. Descriptive statistics (mean and standard deviations) for all variables included in the model that can be found in Table 1.

$T$ tests were conducted with each of the three outcome variables (at year four) with gender and age as the independent variables. There was a significant difference between males $(M=.34)$ and females $(M=.21)$ as it relates to fighting (equal variances not assumed), $t$ $(345.29)=2.84, p<.05$. Differences were also found between male $(M=.23)$ and female $(M=$ $.04)$ participants who reported sexual involvement, $t$ (328.87) $=2.46, p<.05$. No gender differences were found for the participants who reported consuming an alcoholic beverage; $13-$ and 14 -year-olds accounted for $50 \%$ and $43 \%$ of the participants in year four. The group was split in half at age 14, with the older group consisting of students 14 years and older. No significant differences existed for the two sub-groups as it relates to fighting, alcohol consumption, and sexual involvement.

\section{Primary Analyses}

The data fit the two latent growth models well with CFI $=0.98$ and RMSEA $<0.05$ for the model without controlling for covariates and CFI $=0.97$ and RMSEA $<0.04$ for the model with covariates being included.

Results in Figure 1 indicate that first the levels of parental monitoring at baseline (year 1) showed a significant negative effect on risk behavior at year four (standardized coefficient = 0.36, $p<0.01$ ). Second, the level of parental monitoring showed an increasing trend over time with the standardized model coefficients $=0.44,0.63$, and 0.78 in year 2 , year 3 , and year 4 respectively after the level of monitoring in year 1 was fixed to zero. The increments in parental monitoring during the 4-year period also significantly predicted risky problem behaviors at year 4 (standardized coefficients $=-0.72, p<0.01$ ). This coefficient is exactly two-times the coefficient assessing the initial status of parental monitoring on the risk behavior measure.

After controlling a potential confounding effect from parent-child relationship and perceived neighborhood risk, the association between parental monitoring assessed at baseline and child risk behavior was shown to have increased (standardized coefficients $=-0.38, p<0.01$ ) while the association between changes in parental monitoring over time and risk behavior was slightly reduced (standardized coefficient $=-0.68, p<0.01$ ). In addition, data in this model indicated that parent-child relationship showed a positive relationship (standardized coefficient = 0.36, $p<0.01$ ) with increments in parental monitoring over time, although these two were negatively associated at baseline (standardized coefficient $=-0.33, p<0.01$ ). Perceived neighborhood risk was not significantly associated with the increase in parental monitoring over time (standardized coefficient $=0.05, p>0.05$ ); however, it was negatively associated with baseline parental monitoring (standardized coefficient $=-0.18, p<0.01$ ). 
International Journal of Child, Youth and Family Studies (2012) 4: 376-395

\section{Discussion}

This study tested a growth model of parental monitoring over a four-year period in predicting adolescent behavior outcomes. Contrary to our first hypothesis, significant mean level increases for parental monitoring over a four-year period were found. This increase was then found to predict risky problem behavior in year four. Supportive of our second hypothesis, higher reported parental monitoring was associated with less reported youth problem behaviors. The data partially supported our third hypothesis: better parent-child relationships over the fouryear period were associated with a greater increase in monitoring. However, students who initially had higher scores for parent-child relationship reported lower mean monitoring scores, but experienced the greatest amount of growth of parental monitoring over the four-year time frame. Additionally, students who reported witnessing more exposure to alcohol, drugs, and violence in their neighborhoods reported higher levels of parental monitoring.

With the exception of the level of parental monitoring over time, the results were generally consistent with findings from other studies that assessed parental monitoring and child outcomes in North American samples (Dishion \& McMahon, 1998). Specifically, the youth in this sample who reported less involvement in problem behaviors also reported greater parental monitoring (Chilcoat \& Anthony, 1996; Meschke \& Silbereisen, 1997; Richards et al., 2004). The results of this sample provide further evidence for the connection between neighborhood, monitoring, and positive outcomes, such that the youth whose parents provided greater monitoring, reported less involvement in risky problem behaviors even in the presence of less than optimal neighborhood conditions (Baldwin et al., 1990; Beyers et al., 2003).

The unexpected finding of an increase in parental monitoring with advancing age among this sample of Bahamian youth may imply another mechanism impacting the trajectory of parental monitoring in early adolescence. Culture is a possible factor to explain the differences; it is possible that family structure or parenting styles of Bahamian families differ from those in the U.S. and European countries from which much of the monitoring literature is derived. For example, it is common to find more than one generation of Bahamian families living together; thus, even if the primary caregiver is absent or unaware, there are grandparent(s), aunt(s), and/or uncle(s) who are present in the home environment to assist with monitoring youth's activities. Moreover, most youth who reside in the inner city areas of New Providence Island are a part of very small and tightly knit communities, where neighbors are familiar with each other and frequently are related to each other. Therefore, the actions of youth within the community or surrounding area can be accounted for due to the interconnectedness of the community.

Another possible explanation for the increase in parental monitoring among this sample could be the age range included for the analyses; it would be interesting to see if the steady increase of parental monitoring continues, plateaus, or even decreases as the youth move through middle adolescence into their later teen years. Intuitively, it makes sense that at pre-adolescence and into early adolescence, the dependence on parents is still very high and thus "monitoring" may not be as salient a factor with respect to older youth who spend more time with their peers.

An additional finding of this study was that the students who initially reported weaker parent-child relationships over time reported stronger relationships as parental monitoring 
International Journal of Child, Youth and Family Studies (2012) 4: 376-395

continued to increase. This interesting shift may be a function of the dual aspect of parental monitoring reporting where both the child's and the parent's perspectives are important. Research has shown that youth who have better relationships with their parents tend to check in more often than their peers and thus, "monitoring” is higher even if the parents' actions have not increased overtly (Kerns et al., 2001; Soenens et al., 2006). This finding could potentially support a competing conceptualization of parental monitoring initially proposed by Stattin and Kerr (2000) which suggests that self-disclosure on behalf of the youth is more important than the actions of the parent in explaining the relationship between parental monitoring and problem behavior. Additional support for this conceptualization was found in the results of this study, as the participants who reported better parent-child relationships also reported the greatest amount of growth in parental monitoring over time. Whereas the researchers acknowledge the merit of this conceptualization, it was not one of the directions of this study and so it is difficult to draw any stronger conclusions in this regard.

\section{Limitations}

There are several potential limitations of this study. First, these data were obtained from students and parents who agreed to participate in a randomized controlled trial; therefore, although they were randomized to the control condition, they may or may not be representative of Bahamian society in general. Additionally, parental monitoring was measured using only the student reports. As mentioned, parental monitoring is a function of the parent-child relationship as communication is an important aspect of monitoring ( $\mathrm{Li}$ et al., 2000). Results presented here could be strengthened if both parent and student reports were factored into the model and subsequent analyses.

Given that the data used for these analyses were from a longitudinal study, it is noted that attrition was a possible limitation. In this study, there were both drop-outs and students missing for specific time points of data collection; students who missed more than two of the four time points included in these analyses accounted for $7 \%$ of the total sample.

Finally, it should be noted that the data used in these analyses were from a larger study looking at a school-based HIV prevention program and health risk behaviors. The research questions and hypotheses guiding the analyses in this paper differ from the original purpose and were proposed after the data had been collected.

While the literature on parental monitoring is extensive, this study is the first to look at patterns of parental monitoring and its relationship with problem risk behavior specifically in Bahamian youth. This adds to the literature on the function of parental monitoring, as it relates to non-North American cultural contexts. The results of the study have implications specifically for Bahamian families and immediate communities as it relates to decreasing and/or delaying adolescent involvement in risky problem behaviors. 
International Journal of Child, Youth and Family Studies (2012) 4: 376-395

\section{References}

Aalsma, M. C., Liu, G. C., \& Wiehe, S. E. (2011). The role of perceived parent monitoring and support on urban child and adolescent problem behavior. Community Mental Health Journal, 47, 61-66. doi: 10.1007/s10597-009-9251-2

Arnett, J. (1992). Reckless behavior in adolescence: A developmental perspective. Developmental Review, 12(4), 339-373. doi: 10.1016/0273-2297(92)90013-R

Baldwin, A., Baldwin, C., \& Cole, R. (1990). Stress resistant families and stress resistant children. In J. Rolf, A. Masten, D. Cicchetti, K. Neuchterlein, \& S. Weintraub (Eds.), Risk and protective factors in the development of psychopathology (pp. 257-280). Cambridge, UK: Cambridge University Press.

Barnard, K., Morisset, C., \& Spieker, S. (1993). Preventive interventions: Enhancing parentinfant relationships. In C. Zeanah (Ed.), Handbook of infant mental health (pp. 386401). New York: Guildford.

Beyers, J. M., Bates, J. E., Pettit, G. S., \& Dodge, K. A. (2003). Neighborhood structure, parenting processes, and the development of youths' externalizing behaviors: A multilevel analysis. American Journal of Community Psychology, 31(1-2), 35-53. doi: 10.1023/A:1023018502759

Bronfenbrenner, U. (1979). The ecology of human development: Experiments by nature and design. Cambridge, MA: Harvard University Press.

Brook, J. S., Adams, R. E., Balka, E. B., Whiteman, M., Zhang, C., \& Sugerman, R. (2004). Illicit drug use and risky sexual behavior among African American and Puerto Rican urban adolescents: The longitudinal links. Journal of Genetic Psychology, 165(2), 203220.

Byrnes, H. F., Miller, B. A., Chen, M., \& Grube, J. W. (2011). The roles of mothers' neighborhood perceptions and specific monitoring strategies in youths' problem behavior. Journal of Youth and Adolescence, 40(3), 347-360.

Carroll, A., Hemingway, F., Bower, J., Ashman, A., Houghton, S., \& Durkin, K. (2006). Impulsivity in juvenile delinquency: Differences among early-onset, late-onset, and non-offenders. Journal of Youth and Adolescence, 35(4), 519-529.

Chilcoat, H. D., \& Anthony, J. C. (1996). Impact of parent monitoring on initiation of drug use through late childhood. Journal of the American Academy of Child \& Adolescent Psychiatry, 35(1), 91-100. doi: 10.1097/00004583-199601000-00017

Chung, H. L., \& Steinberg, L (2006). Relations between neighborhood factors, parenting behaviors, peer deviance, and delinquency among serious juvenile offenders. Developmental Psychology, 42(2), 319-331. 
International Journal of Child, Youth and Family Studies (2012) 4: 376-395

Cole, M., Stanton, B., Deveaux, L., Harris, C., Lunn, S., Cottrell, L., et al. (2007). Latent class analysis of risk behaviors among Bahamian young adolescents: Relationship between values prioritization and latent class. Social Behavior and Personality, 35(8), 10611076.

Deater-Deckard, K., \& Dodge, K. A. (1997). Externalizing behavior problems and discipline revisited: Nonlinear effects and variation by culture, context, and gender. Psychological Inquiry, 8(3), 161-175. doi: 10.1207/s15327965pli0803_1

Department of Statistics, Bahamas. (2005). Vital statistics report 2005. Retrieved from http://statistics.bahamas.gov.bs/key.php?cmd=view\&id=75.

Department of Statistics, Bahamas. (2004). Bahamas living conditions survey 2001. Retrieved from http://statistics.bahamas.gov.bs/archives.php?cmd=view\&id=2.

Dishion, T. J., Capaldi, D., Spracklen, K. M., \& Li, F. (1995). Peer ecology of male adolescent drug use: Developmental processes in peer relations and psychopathology [Special issue]. Development and Psychopathology, 7(4), 803-824.

Dishion, T. J., \& McMahon, R. J. (1998). Parental monitoring and the prevention of child and adolescent problem behavior: A conceptual and empirical formulation. Clinical Child and Family Psychology Review, 1(1), 61-75.

Dishion, T. J., Nelson, S. E., \& Bullock, B. M. (2004). Premature adolescent autonomy: Amplification of the risk trajectory to young adult problem behavior. Journal of Adolescence, 27(5), 515-530.

Dodge, K. A., Pettit, G. S., \& Bates, J. E. (1994). Socialization mediators of the relation between socioeconomic status and child conduct problems. Child Development, 65(2), 649-665. doi: 10.2307/1131407

Eaton, N. R., Krueger, R. F., Johnson, W., McGue, M., \& Iacono, W. G. (2009). Parental monitoring, personality, and delinquency: Further support for a reconceptualization of monitoring. Journal of Research in Personality, 43(1), 49-59. doi: 10.1016/j.jrp.2008.10.006

Edwards, B., \& Bromfield, L. M. (2009). Neighborhood influences on young children’s conduct problems and pro-social behavior: Evidence from an Australian national sample. Children and Youth Services Review, 31(3), 317-324.

Emery, R. E., \& Forehand, R. (1996). Parental divorce and children's well-being: A focus on resilience. In R. J. Haggerty, L. R. Sherrod, et al. (Eds.), Stress, risk, and resilience in children and adolescents: Processes, mechanisms, and interventions (pp. 64-99). New York: Cambridge University Press. 
International Journal of Child, Youth and Family Studies (2012) 4: 376-395

Erikson, E. H. (1968). Identity, youth and crisis. New York: W. W. Norton \& Co.

Frick, P. J., Christian, R. E., \& Wootton, J. M. (1999). Age trends in the association between parenting practices and conduct problems. Behavior Modification, 23(1), 106-128.

Gomez, M. P., Kimball, A., Orlander, H., Bain, R. M., Fisher, L. D. \& Holmes, K. K. (2002). Epidemic crack cocaine use linked with epidemics of genital ulcer disease and heterosexual HIV infection in the Bahamas: Evidence of impact of prevention and control measures. Sexually Transmitted Diseases, 29(5), 259-265.

Gonzales, N. A., Cauce, A., Friedman, R. J., \& Mason, C. A. (1996). Family, peer, and neighborhood influences on academic achievement among African American adolescents: One year prospective effects. American Journal of Community Psychology, 24(3), 365-387.

Greenwood, P. W., Model, K. E., Chiesa, J., \& Rydell, C. P. (1996). Diverting children from a life of crime. Measuring costs and benefits. Santa Monica, CA: RAND.

Griffin, K. W., Botwin, G. J., Scheier, L. M., Diaz, R., \& Miller, N. L. (2000). Parenting practices as predictors of substance use, delinquency, and aggression among urban minority youth: Moderating effects of family structure and gender. Psychology of Addictive Behaviors, 14(2), 174-184. doi: 10.1037/0893-164X.14.2.174

Hoffman S. (2006). By the numbers - The public costs of teen childbearing. Washington, DC: National Campaign to Prevent Teen Pregnancy.

Huebner, A., \& Howell, L. (2003). Examining the relationship between adolescent sexual risktaking and perceptions of monitoring, communication, and parenting styles. Journal of Adolescent Health, 33(2), 71-78. doi: 10.1016/S1054-139X(03)00141-1

Jarrett, R. L. (1999). Successful parenting in high-risk neighborhoods. The Future of Children, 9(2), 45-50.

Karp, I., O’Louglin, J., Paradis, G., Hanley, J., \& Difranza, J. (2005). Smoking trajectories of adolescent novice smokers in a longitudinal study of tobacco use. Annual Epidemiology, 15, 445-452.

Keijsers, L., Loeber, R., Branje, S., \& Meeus, W. (2011). Bidirectional links and concurrent development of parent-child relationships and boys offending behavior. The Journal of Abnormal Psychology, 120(4), 878-889. doi: 10.1037/a0024588

Kerns, K. A., Aspelmeier, J. E., Gentzler, A. L., \& Grabill, C. M. (2001). Parent-child attachment and monitoring in middle childhood. Journal of Family Psychology, 15(1), 69-81. 
International Journal of Child, Youth and Family Studies (2012) 4: 376-395

Leventhal, T., \& Brooks-Gunn, J. (2000). The neighborhoods they live in: The effects of neighborhood residence on child and adolescent outcomes. Psychological Bulletin, 126(2), 309-337.

Leventhal, T., \& Brooks-Gunn, J. (2011). Changes in neighborhood poverty from 1990 to 2000 and youth's problem behaviors. Developmental Psychology, 47(6), 1680-1698. doi: $10.1037 / \mathrm{a} 0025314$

Li, X., Stanton, B., \& Feigelman, S. (2000). Impact of perceived parental monitoring on adolescent risk behavior over four years. Journal of Adolescent Health, 27(1), 49-56.

Loeber, R., \& Dishion, T. (1983). Early predictors of male delinquency: A review. Psychological Bulletin, 94(1), 68-99. doi: 10.1037/0033-2909.94.1.68

Lynam, D. R., \& Miller, J. D. (2004). Personality pathways to impulsive behavior and their relations to deviance: Results from three samples. Journal of Quantitative Criminology, 20(4), 319-341. doi: 10.1007/s10940-004-5867-0

Malecki, C. K., \& Demaray, M. K. (2006). Social support as a buffer in the relationship between socioeconomic status and academic performance. School Psychology Quarterly, 21(4), 375-395.

Masten, A. S. (2001). Ordinary magic: Resilience processes in development. American Psychologist, 56(3), 227-238.

Meschke, L., \& Silbereisen, R. K. (1997). The influence of puberty, family processes, and leisure activities on the timing of first sexual experience. Journal of Adolescence, 20(4), 403-418.

Moffitt, T. E. (1993). Adolescence-limited and life-course-persistent antisocial behavior: A developmental taxonomy. Psychological Review, 100(4), 674-701.

Mrug, S., \& Windle, M. (2009). Mediators of neighborhood influences on externalizing behavior in preadolescent children. Journal of Abnormal Child Psychology, 37(2), 265280.

Park, S., Weaver, T. E., \& Romer, D. (2009). Predictors of the transition from experimental to daily smoking among adolescents in the United States. Journal for Specialists in Pediatric Nursing, 14(2), 102-111.

Patterson, G. R., DeBaryshe, B. D., \& Ramsey, E. (1989). A developmental perspective on antisocial behavior. American Psychologist, 44(2), 329-335.

Pharo, H., Sim, C., Graham, M., Gross, J., \& Hayne, H. (2011). Risky business: Executive function, personality, and reckless behavior during adolescence and emerging adulthood. Behavioral Neuroscience, 125(6), 970-978. doi: 10.1037/a0025768 
International Journal of Child, Youth and Family Studies (2012) 4: 376-395

Preacher, K. J., Wichman, A. L., MacCallum, R. C., \& Briggs, N. E. (2008). Latent growth curve modeling. Thousand Oaks, CA: Sage.

Richards, M. H., Miller, B. V., O’Donnell, P. C., Wasserman, M. S., \& Colder, C. (2004). Parental monitoring mediates the effects of age and sex on problem behaviors among African-American urban young adolescents. Journal of Youth and Adolescence 33(3), 221-233.

Romano, E., Tremblay, R. E, Boulerice, B., \& Swisher, R. (2005). Multilevel correlates of childhood physical aggression and prosocial behavior. Journal of Abnormal Child Psychology, 33(5), 565-578. doi: 10.1007/s10802-005-6738-3

Ryan, L. G., Miller-Loessi, K., \& Nieri, T. (2007). Relationships with adults as predictors of substance use, gang involvement, and threats to safety among disadvantaged urban high-school adolescents. Journal of Community Psychology, 35(8), 1053-1071.

Sameroff, A. J., Peck, S. C., \& Eccles, J. S. (2004). Changing ecological determinants of conduct problems from early adolescence to early adulthood. Development and Psychopathology, 16(4), 873-896. doi: 10.1017/S0954579404040052

Sampson, R. J. (1997). Collective regulation of adolescent misbehavior: Validation results from eighty Chicago neighborhoods. Journal of Adolescent Research, 12(2), 227-244.

Schafer, J. L. (1997). Analysis of incomplete multivariate data. New York: Chapman \& Hall.

Shaw, D. S., Bell, R. Q., \& Gilliom, M. (2000). A truly early starter model of antisocial behavior revisited. Clinical Child and Family Psychology Review, 3(3), 155-172.

Smetana, J. G., Crean, H. F., \& Daddis, C. (2002). Family processes and problem behaviors in middle class African-American adolescents. Journal of Research on Adolescence, 12(2), 275-304.

Soenens, B., Vansteenkiste, M., Luyckx, K., \& Goossens, L. (2006). Parenting and adolescent problem behavior: An integrated model with adolescent self-disclosure and perceived parental knowledge as intervening variables. Developmental Psychology, 42(2), 305318. doi: 10.1037/0012-1649.42.2.305

Stanton, B., Black, M., Feigelman, S., Riardo, I., Galbraith, J., Li, X., et al. (1995). Development of a culturally, theoretically and developmentally based survey instrument for assessing risk behaviors among African-American early adolescents living in urban low income neighborhoods. AIDS Education and Prevention: An Interdisciplinary Journal, 7(2), 160-177.

Stattin, H., \& Kerr, M. (2000). Parental monitoring: A reinterpretation. Child Development, 71(4), 1072-1085. 
International Journal of Child, Youth and Family Studies (2012) 4: 376-395

Steinberg, L. (2007). Risk-taking in adolescence: New perspectives from brain and behavioral science. Current Directions in Psychological Science, 16(2), 55-59.

Steinberg, L. (1999). Adolescence (5th ed.). New York: McGraw-Hill.

Steinberg, L., \& Morris, A. S. (2001). Adolescent development. Annual Review of Psychology, 52, 83-110. doi: 10.1146/annurev.psych.52.1.83

Stoolmiller, M. (1994). Antisocial behavior, delinquent peer association and unsupervised wandering for boys: Growth and change from childhood to early adolescence. Multivariate Behavioral Research, 29(3), 263-288.

Tapert, S. F., Aarons, G. A., Sedlar, G. R., \& Brown, S. A. (2001). Adolescent substance use and sexual risk-taking behavior. Journal of Adolescent Health, 28(3), 181-189.

Trim, R. S., Meehan, B. T., King, K. M., \& Chassin, L. (2007). The relation between adolescent substance use and young adult internalizing symptoms: Findings from a high-risk longitudinal sample. Psychology of Addictive Behaviors, 21(1), 97-107. doi: 10.1037/0893-164X.21.1.97

Vanderbilt-Adriance, E., \& Shaw, D. (2008). Protective factors and the development of resilience in the context of neighborhood disadvantage. Journal of Abnormal Child Psychology, 36(6), 887-901.

Wight, D., Williamson, L., \& Henderson, M. (2006). Parental influences on young people. Journal of Adolescence, 29(4), 473-494. 
International Journal of Child, Youth and Family Studies (2012) 4: 376-395

Table 1. Correlations and descriptive statistics of all variables

\begin{tabular}{|c|c|c|c|c|c|c|c|c|c|c|c|c|}
\hline & Variables & 1 & 2 & 3 & 4 & 5 & 6 & 7 & 8 & 9 & 10 & 11 \\
\hline 1 & Gender & 1 & & & & & & & & & & \\
\hline 2 & Age & -.06 & 1 & & & & & & & & & \\
\hline 3 & Neighborhood Problems & .06 & $-.16^{* *}$ & 1 & & & & & & & & \\
\hline 4 & Parent-child relationship & .01 & -.08 & $.23^{* *}$ & 1 & & & & & & & \\
\hline 5 & Monitoring (Year 1) & $.12^{* *}$ & $-.10^{*}$ & $.50^{* *}$ & $.28^{* *}$ & 1 & & & & & & \\
\hline 6 & Monitoring (Year 2) & $.15^{* *}$ & -.06 & -.02 & -.04 & $.12^{*}$ & 1 & & & & & \\
\hline 7 & Monitoring (Year 3) & $.24^{* *}$ & $-.13^{* *}$ & .00 & .00 & .06 & $.40^{* *}$ & 1 & & & & \\
\hline 8 & Monitoring (Year 4) & $.21^{* *}$ & $-.17^{* *}$ & .03 & .03 & $.13^{*}$ & $.26^{* *}$ & $.44^{* *}$ & 1 & & & \\
\hline 9 & Involved in a fight & $-.14^{* *}$ & .02 & -.01 & -.01 & -.05 & -.04 & $-.12^{*}$ & $-.18^{* *}$ & 1 & & \\
\hline 10 & Drank alcohol & -.03 & .01 & .02 & -.01 & -.05 & $-.10^{*}$ & $-.17^{* *}$ & $-.19^{* *}$ & $.25^{* *}$ & 1 & \\
\hline 11 & Had sex & $-.13^{*}$ & .02 & -.06 & -.02 & .01 & -.08 & $-.11^{*}$ & $-.12^{*}$ & $.17^{* *}$ & $.13^{* *}$ & 1 \\
\hline$M$ & & 1.54 & 10.40 & 2.21 & 2.05 & 3.67 & 4.18 & 4.19 & 4.14 & .26 & .25 & .13 \\
\hline$S D$ & & .50 & .64 & 1.37 & 1.49 & 2.01 & 1.14 & 1.19 & 1.01 & .44 & .64 & .75 \\
\hline
\end{tabular}

\footnotetext{
**. Correlation is significant at the 0.01 level (2-tailed)
}

*. Correlation is significant at the 0.05 level (2-tailed). 
International Journal of Child, Youth and Family Studies (2012) 4: 376-395

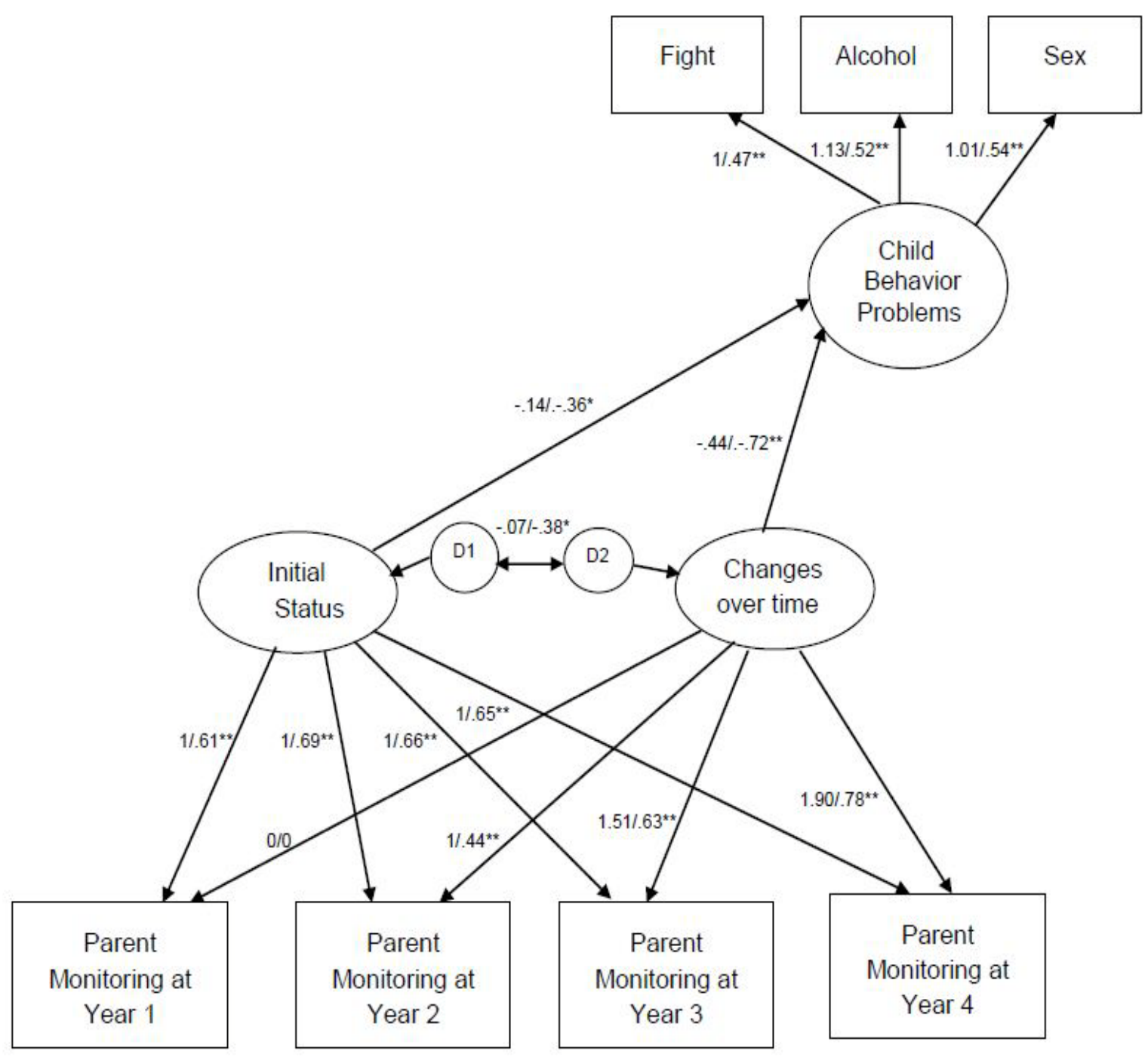

Figure 1. Basic growth model of parental monitoring over four years

Note. The number above the slash is the modeling results and the number under the slash is the standardized modeling results.

${ }^{* *} p<0.001$

${ }^{*} p<0.05$ 
International Journal of Child, Youth and Family Studies (2012) 4: 376-395

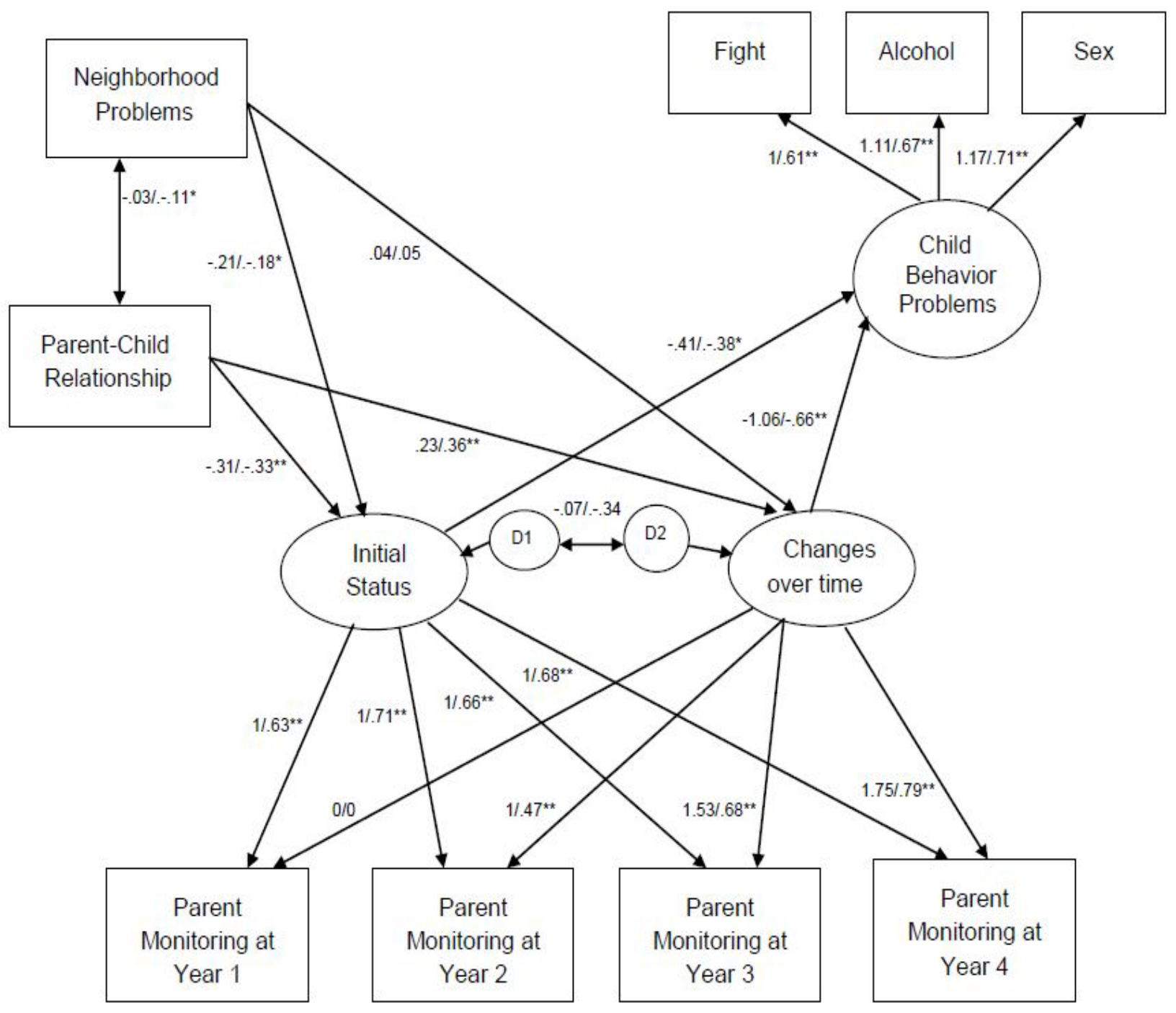

Figure 2. Growth model of parental monitoring with covariates

Note. The number above the slash is the modeling results and the number under the slash is the standardized modeling results.

$* * p<0.001$

${ }^{*} p<0.05$ 